\title{
INTERNATIONAL SCIENTIFIC SCHOOL "INTELLIGENT ROBOTRONICS"
}

\author{
PRYANICHNIKOV, V.
}

Abstract: The article discusses problems, carried out within the framework of the research, implementation project "Intelligent Robotronics" on the basis of the Agreement dated 05.03.2016 on joint work of KIAM Russian Academy of Sciences with IINET RSUH, MSTU "Stankin" together with universities and organizations. Complex of works on the creation of intelligent mobile robots for various purposes led us to the need to find solutions of the key problems of such developments, as finding a proper interfaces robot-operators, reliable mechanisms of integration and non-stop transformation of the software, synchronization of all the control and sensing processes and, of course, the intellectualizing of the groups of robots. The article discusses the features of using remote sensors as feedbacks for controlling service robots. One of the most significant problems is the harmonization of the frequency characteristics of microprocessors, control computers and sensor capabilities, including delays and data distortion. The purpose of the research is to increase the autonomy and flexibility of mobile robotic complexes, develop algorithms for effective robot control, that take into account the features of remote sensors and applied logic filters, as well as the implementation of distributed mechatronic systems. The article summarizes the campaigns of a team of researchers, involved in the project of creating a new generation of service robots.

Key words: Intellectualization technologies for service robots, remote sensors in the feedback loops in robotics, control synergies, technologies of AI.
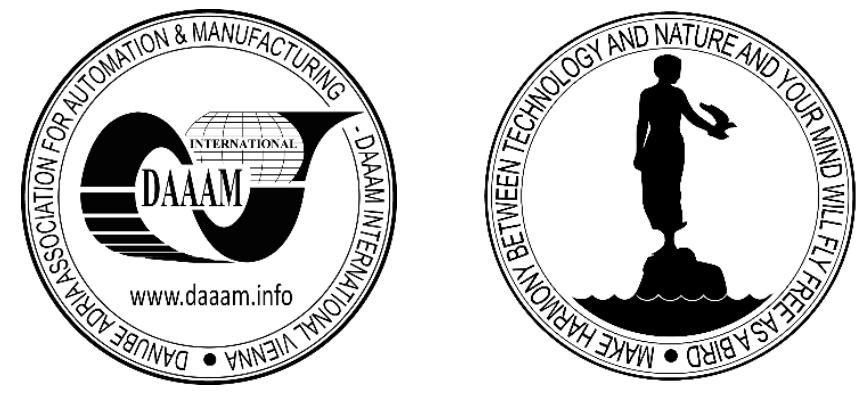

Authors' data: Leading researcher, Dr.techn.sc. head of chair Pryanitchnikov *** V[alentin], *KIAM Russian Academy of Sciences, **International Institute for New Educational Technologies RSUH, Miusskaya sq. 4 \& 6 Moscow 125047 Russia, v.e.pr@yandex.ru

This Publication has to be referred as: Pryanichnikov V[alentin] (2021). International Scientific School "'Intelligent Robotronics"", Chapter 21 in DAAAM International Scientific Book 2021, pp.251-262, B. Katalinic (Ed.), Published by DAAAM International, ISBN 978-3-902734-31-0, ISSN 1726-9687, Vienna, Austria DOI: $10.2507 /$ daaam.scibook.2021.21 


\section{Introduction}

Creation of intelligent mobile robots for various purposes (medical care, guard) are facing the key problems - finding a proper interfaces with operators, reliable mechanism for upgrading software and hardware in the conditions of changing versions and meeting the conflicting requirements of various customers (Pryanichnikov et al., 2018). The main difficulty is implementing remote sensors in feedbacks loops, harmonization the frequencies of devices with the microprocessors abilities, including avoiding delays of sensor signals and data distortion. We need to increase the autonomy and flexibility of mobile robotic complexes, develop algorithms for effective robot control, using the remote sensors with logic filters (Pryanichnikov \& Shapovalov, 2019) - (Pryanichnikov, 2008), (Davydov et al., 2017) - (Ksenzenko et al., 2017). Development of such complicated real time software, is necessary to use continuous integration and deployment systems to automate the development process. The article is based on our works (Pryanichnikov et al., 2018) - (Stepanova \& Pryanichnikov, 2020), (Davydov et al., 2017) - (Ksenzenko et al., 2017)

\section{CoBots - the telepresence technologies and distant sensors in feedback loops}

The Intelligent Robotronics project is aimed at implementing effective technologies for mobile service robots and their basic elements, using additive and laser tools, CNC milling machines for rapid prototyping, as well as developing and applying ultrasonic and TV sensors, lidars to provide intelligent control using the created dictionary of synergies for the implementation of typical movements.

The test results of the created Amur-307 robots confirm their operability and the high efficiency of the proposed approaches. Network integration software made it possible to unify the management of heterogeneous robots, including in the mode of their digital counterparts, allowing the use of telepresence capabilities. Moreover, several operators (or trainees) have access to each robot at once, and partial on-line reprogramming capabilities are also provided.

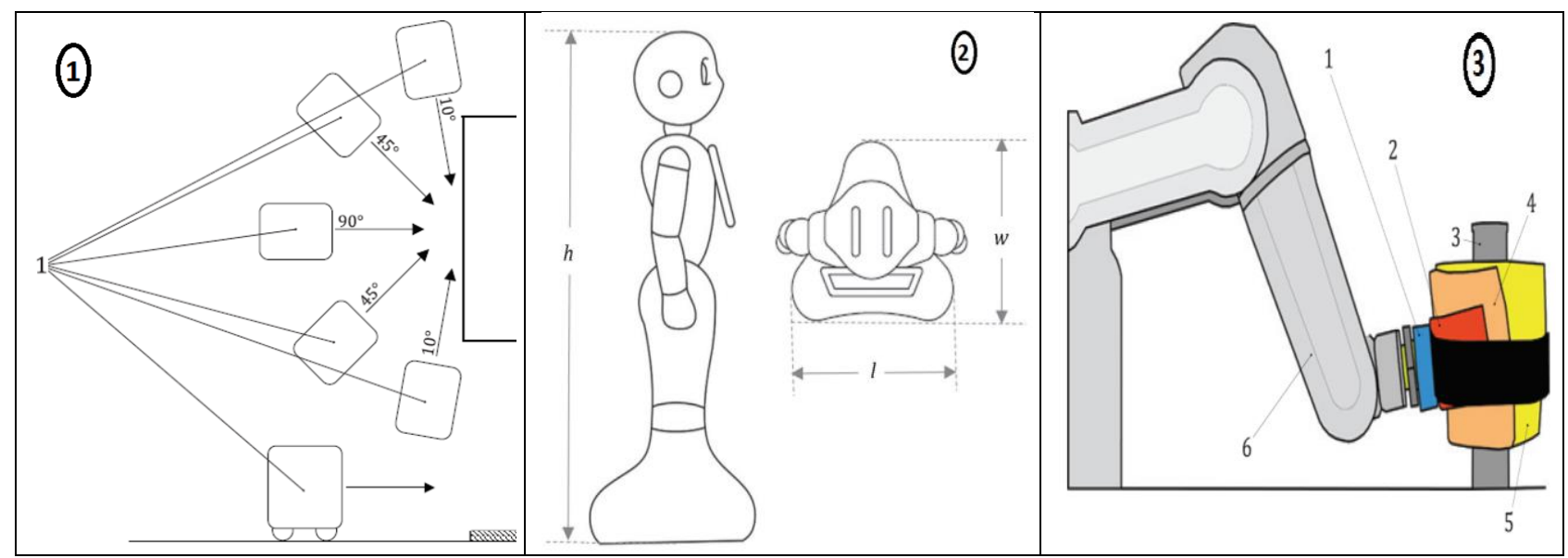

Fig. 1. Regulation and testing of the consequences of robot-human interaction:

1 - when encountering obstacles, it is necessary to prevent the consequences leading to an uncontrolled rebound of the robot from it; 2 - it is necessary to maintain the ratio of robot and human sizes for presentation, service robots; 3 - it is necessary to differentially limit force effects with objects and a person 
These robotic complexes have been developed as the main part of an antivirus system for medical institutions, and in fact are CoBots, which protect staff and patients from collisions with them and ensure effective navigation in a changing environment due to a complex of remote sensors. Let's clarify the terminology fixed in the new State Standards of the Russian Federation and ISO for the designation of robots working in direct contact with people. Definitions:

- 1 . Robots $=<$ Industrial robots $\mid$ Service robots >

- 2. If they are able to move under their own control, then this is < Mobile robot | Mobile Platforms $>$

- 3. $\langle$ CoBot $\rangle=$ Robots, if at the same time they safety requirements of operation being provided in a joint space with a human/operators (in working space), then it is a $\langle$ CoBot $>$ or a collaborative robot (Fig.1).

\section{Basic techniques of intellectualization of robot control}

Our robots have intelligent sensor-control systems, based on the following principles:

- 1. Graphs and Petri nets are used as a synchronization mechanism, including the synergy control construction (executing algorithms, fig. 2).

- 2. Penta-logic for designing expert schemes and logic filters with interpolation extrapolation to synchronize data flows and control circles/loops.

- 3. Brute force search algorithms are used in mission planners, including algorithms on the base of neural networks and parallel computing, pattern recognition. At the moment, identification of markers, doors and handles on them, staff and patients' faces are implemented by brief observation of them and then memorizing names and status, then fixing this in the database with the permission of the operator (fig. 4,5).

- 4. Traditional feedback-based regulators with contact and remote sensors, distributed mechatronic devices and manufacturing

- 5. Integration software, that provides evolutionary development of the system.

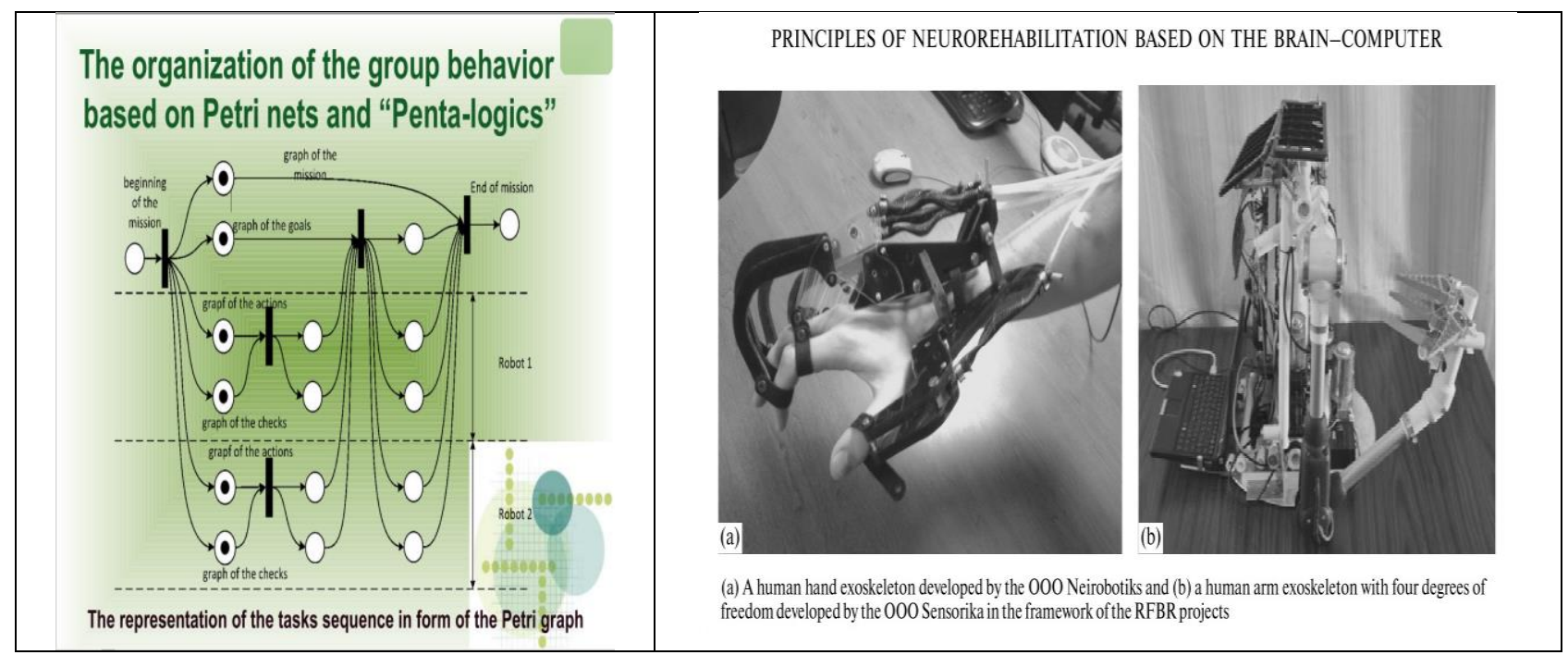

Fig. 2. Building the interaction of sensory and motor activity to control manipulators in contact with a changing environment and with a person 
The listed approaches 1-5 were mainly realized; last results of the iintellectualization technologies for sensor-control systems of service robots were published, for example in last DAAAM proceedings in 2021-2019 years:

1. Graphs and Petri nets as a synchronization mechanism, synergy control constructions, DAAAM-2021, Plotnikov A. et al. (section 4)

2. Penta-logic for designing expert schemes and logic filters with interpolation and extrapolation (also Branching time Logics) DAAAM-2020 (038) Khelemendik, R. \& Pryanichnikov, V. and Contradictory Reasoning in Connection with the Problems of Intelligent Robotronics DAAAM-2021 Travushkina A., Aryskin A. et al. (section 5)

3. Brute force search algorithms: planners, based on neural networks and parallel computing, pattern recognition (faces, doors, handles, small objects, markers), DAAAM-2019 (160) Shipovalov, E. \& Pryanichnikov, V.: Automated Mission Planning for Mobile Robots Using Ebedded GPU

4. Traditional feedback-based regulators with contact and remote sensors, distributed mechatronic devices and manufacturing, DAAAM-2020 (047) Stepanova, D. \& Pryanichnikov, V.: Optical Communication Terminal For Mobile Robots

5. Integration software, that provides evolutionary development of robotic systems, DAAAM-2021, Tarasov R., Kolesov Yu. et al. (section 3)

\section{Comparison of the duration of control cycles for robots with remote sensors, the construction of motor synergies}

The main problems of constructing control cycles of collaborative robots are synchronization and integration of several feedbacks with the elimination of contradictions between their indications.

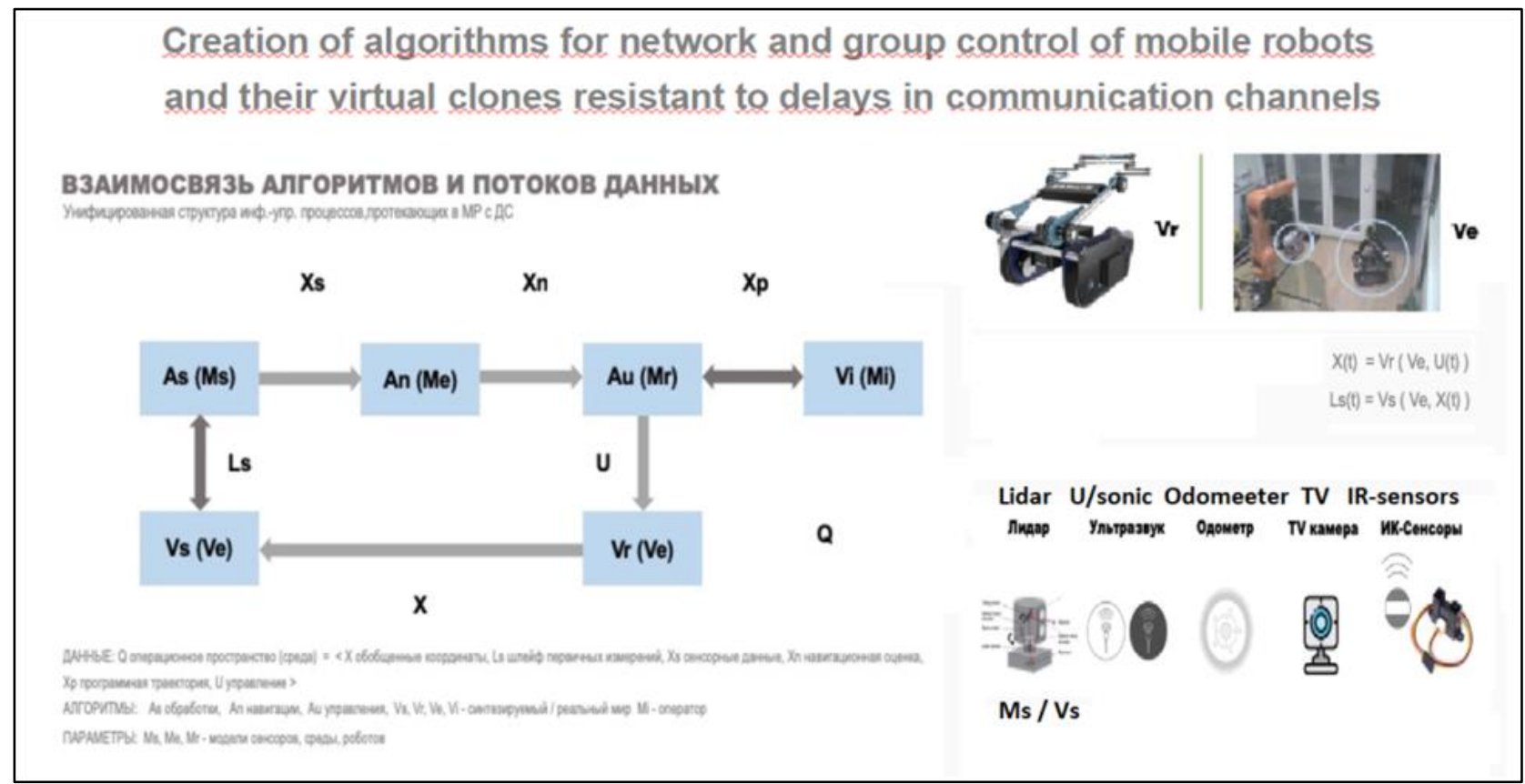

Fig. 3. Building synergies and it's sensory support 
In order to capture particularly heavy objects located significantly above the center of mass, control synergies of the robot manipulator drives were designed based on reverse visual and ultrasonic rangefinder connections (Fig.4, bionic analogues of such control were also developed in (Pryanichnikov \& Shapovalov, 2019), (Pryanichnikov, 2008), (Laurent, 1995). The main idea of the robot's sequence of actions is to grab an object at the first stage, initially without lifting it from the support (table), to estimate its weight. Then, based on a mathematical model (it turned out to be sufficient to use a kinetostatic approach), calculate the parameters of the drives so, that when lifting an object (load) and shifting it "towards itself", at the same time, the robot's mobile platform abruptly moved towards the captured object.

These coordinated actions (synergy) make it possible to avoid tipping the robot forward. The most important condition for the success of such an operation is to receive data from sensors (Fig.4, right) at the right pace and calculate the feasibility of transferring load to the robot in real time based on a simplified semi-analytical dynamics model. When designing the described synergy, an preliminary analysis of the problem on the digital twin of the robot, parameterization of movements is required, and only then it becomes possible to successfully reproduce such a similar sequence of actions (i.e. synergy) for various variants of the relative position of the robot and the load. To quickly solve the inverse kinematic problem, it was possible to adapt an approximate algorithm (Sodnik et al., 2006)

Similar synergies need to be formed (using mathematical models and display training) for opening and closing doors, pressing buttons, and the like. From a programmatic point of view, a graph of performed actions is formed, a graph of sensory checks of the end of individual operations and the definition/measurement of operation parameters. Identification of the achievement of target points and movement parameters is performed using a vision system (VS), contact sensors and encoders. Thus, objects are captured both from the floor and from various heights of tables/stands up to $85 \mathrm{~cm}$, and the task of capturing handles for opening doors is also solved.

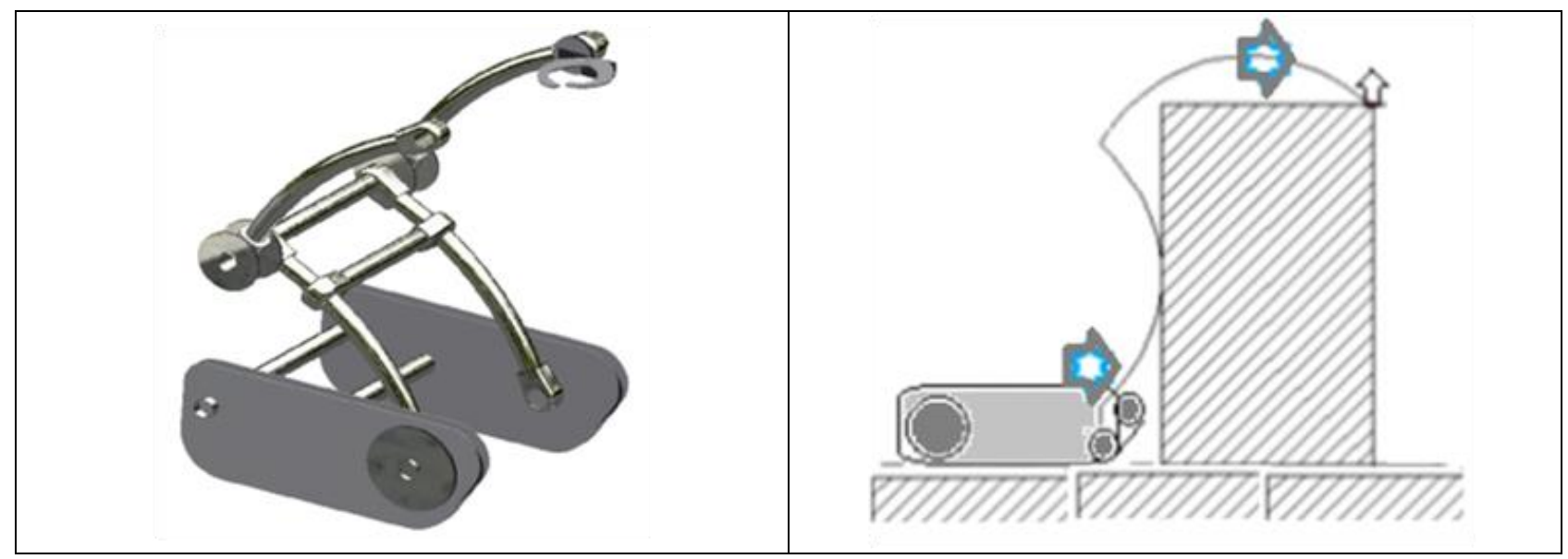

Fig. 4. The placement of ultrasonic rangefinders is shown by a horizontal arrow on a tracked mobile platform, a vertical arrow shows a tactile sensor next to a video camera on the upper link of the manipulator. 


\section{Use of vision systems for targeting and navigation}

The technology of localization of a mobile robot and route planning has been developed (Pryanichnikov \& Shapovalov, 2019), (Pryanichnikov, 2008) for telemedicine tasks, for work/patrolling in a system of interconnected rooms. The mobile camera determines linear coordinates (relative to the coordinate system associated with the robot body) and observation angles of markers on walls/ceiling and on manipulated objects, recognizing up to 1000 Aruca-codes. The most acceptable size of these markers was experimentally set to $150 \times 150 \mathrm{~mm}$ (for localization of robots) and $50 \times 50$ (for identification of objects), the number of cells is 6x6 (Fig.3). Since a priori it is assumed, that the markers have known coordinates in the room system (in the operating environment) or have an approximate location marking the semantic zone, after their identification (by the code found), the onboard algorithm on the robot calculates the coordinates of the robot itself.

The identification program is written in Python, several variants of triangulation and recognition of Aruca-codes are implemented. The error in determining the range (from 1 to $20 \mathrm{~m}$ ) to the marker was from 5 to $10 \%$, the identification speed was from 10 to $30 \mathrm{~ms}$ when using even low-quality wide-angle TV cameras (such as on-board tablet cameras). For the final determination of the purposes of movement, these data are compared with data from paired ultrasonic locators and with data from VS based on a neural network trained to identify doors with lever and round handles on them (Fig.5). This figure on the left shows 4 pairs of sensors and the results of comparing their readings.

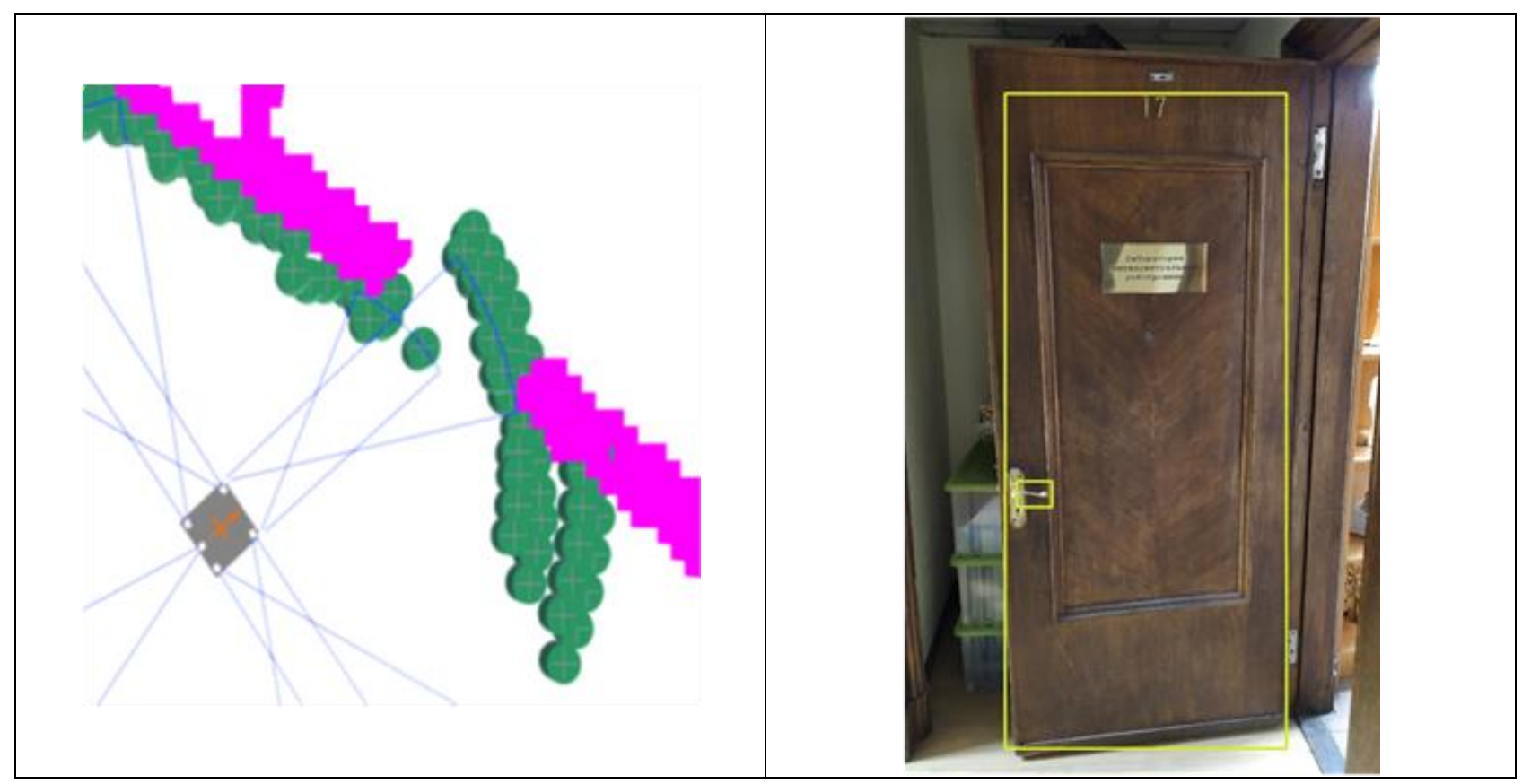

Fig. 5. Identification of doors according to ultrasonic sensors (on the left) and door images (the resolution of the VS camera is only 800x600 pixels). A trained neural network identifies both one and several doors (opened or closed), with or without handles. This provides stable targeting for pointing a manipulator with two gripping devices - specialized for doors and general purpose for grabbing small objects. 


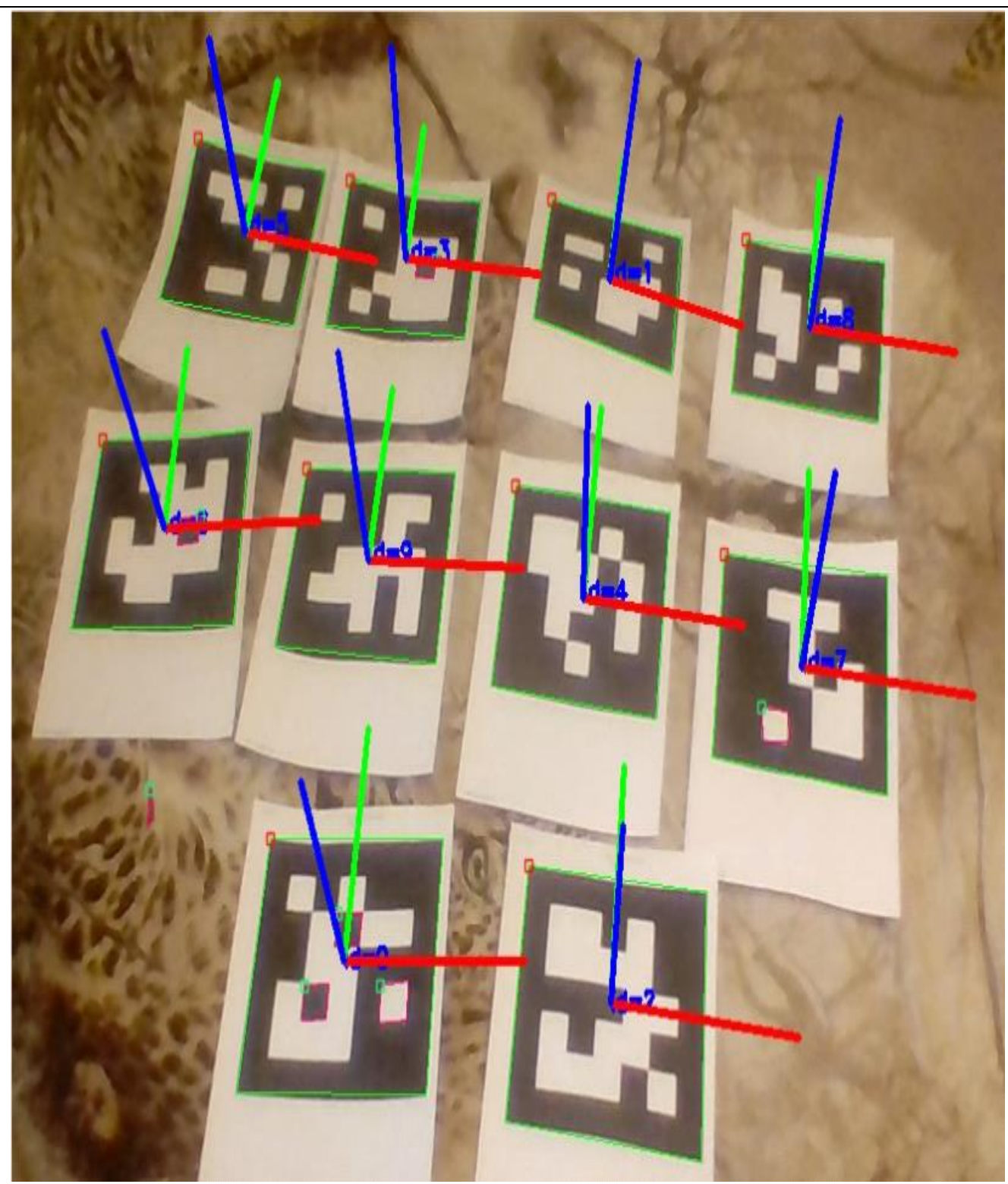

Fig. 6. Simultaneous identification of 10 Aruca markers (out of 1000) and their coordinates relative to the camera. Markers are placed on objects to indicate the transportation route along the planned routes

The applications of the approaches proposed in the work to the construction of algorithms for localization, identification of objects of manipulation and movement seem to be quite effective and relatively simple to implement within the hardware capabilities of the robots we are developing for various purposes (Fig.1-6).

For underwater robots, markers should be used to indicate the docking points of a satellite robot with a walking vehicle, and ultrasonic locators make it possible to avoid obstacles and ensure following along the bottom relief at a given distance in semi-automatic and automatic modes. The VolgSTU (Department of Theoretical Mechanics) has developed, manufactured and tested an underwater walking apparatus weighing about $200 \mathrm{~kg}$ with a uniquely large traction force of up to $300 \mathrm{~kg}$ on the Lake Baikal and the White Sea. Robot uses the microprocessor system of frequency control of drives created by us on the basis of network technologies. Access to it via the robotarium has been tested. 
A system has been developed and manufactured for contactless recharging of batteries, and for transmitting data, control signals through salt water, using electromagnetic and ultrasonic channels for the small satellite robots that accompany a large walking base at a distance of up to $100 \mathrm{~m}$.

\section{Development of distributed mechatronic systems}

Recently, a relatively new type of robots and mechatronic devices has appeared and occupies an increasing segment of research - autonomous agents, that actively interact, but at the same time work autonomously, without exchanging control signals. We have considered such devices, that should work synchronously with minimal delays and carry out oncoming guidance of laser beams from long distances to ensure communication of several objects - satellites or ground stations, robots. Although this problem has been developed for a long time, acceptable compact solutions have not been found (Frolov et al., 2013) - (Stepanova \& Pryanichnikov, 2020).

The task is relevant in the Ministry of Emergency Situations for managing groups of mobile robots and for inter-satellite communication. In distributed mechatronic systems, the main problem is to ensure the interconnected operation of devices and the transfer of useful information between them. Compared with existing technologies of data transmission using radio waves, the technology of wireless transmission of information using an optical beam is promising for communication of robotic systems at distances from several tens of meters to hundreds of kilometres at high speed.

The main obstacle in the use of this technology in distributed robotic systems, limiting the scope and speed of data transmission, is the creation of high-speed mechatronic devices, that guarantee the counter pointing of optical terminals at each other and ensure the formation of feedback, regardless of the movement of controlled objects. The key issues of their creation are the search for such optimal and interdependent parameters as the width of the optical beam divergence, guidance accuracy, power consumption of the communication terminals, data transfer rate. It is necessary to test subsystems and search for rational in terms of weight, size, energy and functional characteristics of a high-speed mechatronic system of a two-axis drive guidance, capture and tracking systems. It was necessary to develop a drive control system using an optical signal as feedback, to create a methodology for implementing a tracking algorithm for an FPGA guidance system.

The developed algorithms are based on high-speed image processing, using FPGAs in combination with algorithms for oncoming search of laser terminals using predictive motion models. The obtained results have been comprehensively experimentally verified in model and real conditions, see also work (Pryanichnikov, 2008). The accuracy of the guidance turned out to be almost an order of magnitude better, than the angular pixel sizes, and the speed provided (processing time of 1 frame) did not exceed $0.002 \mathrm{~s}$, which provides real-time control. The developed complex of technological and computational techniques, constructed mathematical models allows you to create distributed mechatronic systems of a new type (Fig.6), performing counter homing and implementing new high-speed algorithms for finding and capturing targets. 


\section{Industrial transport robots with a set of automation for workshop control, using Industry 4.0 technology and big-data processing}

Another application of the control intellectualization technologies being developed is Industry 4.0. We have developed, installed and delivered industrial automation control boxex (30 pcs) to factory workshops, developed a methodology and simulation software for the logical analysis of hundreds of recipes and the design of secure remote control.

The system is implemented to control 60 asynchronous drives of industrial transport (more than 20 trolleys weighing up to 2 tons each) and to control equipment drives (power consumption from 0.75 to $33 \mathrm{~kW}$ ), control of 30 electric valves and a microprocessor-based polling system of 70-80 feedback sensors (five types of sensors with data removal and processing frequencies of more, than $20 \mathrm{Khz}$ ) is implemented in parallel.

The technology of predictive certification of industrial equipment for the organization of proactive repairs based on the analysis of the results of long-term remote data collection is proposed.

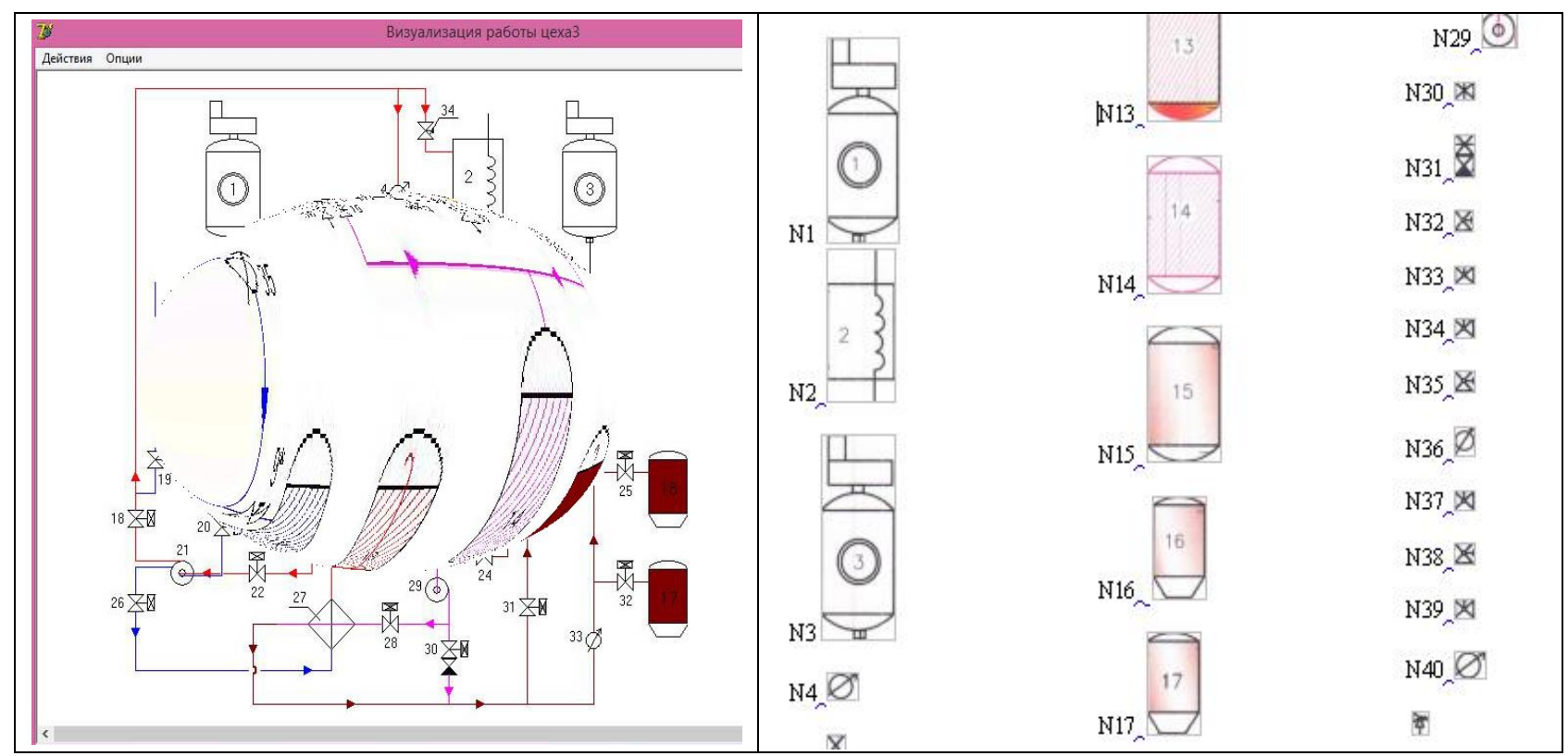

Fig. 7. Building the interaction of sensory and motor activity for the control of the shop transport and contacting with a the changing environment and with a persons. Formalization of shop processes of production control

\section{Conclusions}

Despite the apparent diversity of the developed robotic systems with remote sensors as feedbacks, they have a common problem - the need to analyze the frequency capabilities of the control microprocessors and sensors used. 
The design of "intelligent" control algorithms primarily solves the problem of building the interaction of software modules, matching the frequencies of data exchange and control signals based on the natural intelligence of developers, fragmentation and unification of insufficiently coordinated software and hardware developments of various authors from our team.

To solve this complex problem, it was necessary to develop a voluminous package of integration software and technology for its application using digital twins, unified interfaces operator-robot and robot-mechatronic devices (R.B.Tarasov, Yu.A.Kolesov, S.R.Eprikov). As a result of the work of the created software package, after the assembly and publication of the release, the package is installed by the user on the robot or updated from the project repository. Thus, the mechanism of continuous development, continuous integration and continuous software deployment of complex autonomous and supervisory service robots for actual practical applications is implemented.

\section{References}

Pryanichnikov V.E., Chernyshev V.V., Arykantsev V.V., Aryskin A.A., Eprikov S.R., Ksenzenko A.Ya., Petrakov M.S. (2018). Enhancing the Functionality of the Groups of Autonomous Underwater Robots, Proceedings of the 29th DAAAM International Symposium, pp.1319-1325, B. Katalinic (Ed.), Published by DAAAM International, ISBN 978-3-902734-20-4, ISSN 1726-9679, Vienna, Austria DOI: 10.2507/29th.daaam.proceedings. 190.

Pryanichnikov V.E., Shapovalov E.A. Application of graphical accelerators for automatic planning with heuristic search in the state space. // Intelligent adaptive robots (Special issue of the journal - Information measuring and control systems, vol.16, No. 12), Moscow: Radiotechnika (Radio Engineering), vol.14, No. 1-2, 2019, ISSN 20700814, pp.61-67, DOI 10.18127/j20700814-201812-07. (In Russian)

Pryanichnikov V.E. Algorithmic means of providing remote sensors for mobile robots / Pryanichnikov V.E.// Mechatronics, automation, control. - 2008. - № 10(91). Pp.10-21. (Pryanichnikov V.E. Algoritmicheskoe obespechenie distancionny`x sensorov mobil'ny`x robotov / Pryanichnikov V.E. // Mexatronika, avtomatizaciya, upravlenie. - 2008. - №10(91). - S.10-21. In Russian)

Pryanichnikov V.E. Combination of ultrasound functions and linear drive software control/ Pryanichnikov V.E.// Devices+ automation. - 2008. - No. 12. - pp.22-29. (Pryanichnikov V.E. Sovmeshhenie fil tracii ul'trazvukovy`x danny`x i programmnogo upravleniya linejny`m privodom / Pryanichnikov V.E.// Pribory`avtomatizaciya. - 2008. - №12. - S.22-29. In Russian)

Biologically adequate principles of human exoskeleton control/ A.A. Frolov, E.V.Biryukova, P.D.Bobrov, A.K.Platonov, V.E.Pryanichnikov.// Informationmeasuring and control systems" (vol. Intelligent Adaptive Robots", vol.8, No. 1-2), Moscow: Radio Engineering, 2013, vol.11, No. 4. - pp.7-18, ISSN 2070-0814. 
(Biologicheski adekvatny`e principy` upravleniya e`kzoskeletom ruki cheloveka / A.A. Frolov, E.V. Biryukova, P.D. Bobrov, A.K. Platonov, V.E. Pryanichnikov. // Informacionno-izmeritel`ny`e i upravlyayushhie sistemy` (vy`p. Intellektual`ny`e adaptivny’e roboty’, t.8, № 1-2), M.: Radiotexnika, 2013, t.11, № 4. -S.7-18, ISSN 2070-0814, in Russian)

Methods of biomechatronics of the human hand simulator / A.K. Platonov, A.A. Frolov, E.V. Biryukova, V.E. Pryanichnikov, S.N. Yemelyanov // Preprints of M.V.Keldysh IPM RAS 2012. No. 82. 40 p. URL: http://library.keldysh.ru/preprint.asp?id=2012-82 (in Russian)

Stepanova, D. \& Pryanichnikov, V. (2020). Optical Communication Terminal For Mobile Robots, Proceedings of the 31st DAAAM International Symposium, pp.03340340, B. Katalinic (Ed.), Published by DAAAM International, ISBN 978-3-90273429-7, ISSN 1726-9679, Vienna, Austria DOI: 10.2507/31st.daaam.proceedings.047

B. Laurent, "SILEX: Overview on the European optical communications programme," Acta Astronautica, vol. 37, pp. 417-423, Oct. 1995

Z. Sodnik, B. Furch, and H. Lutz, "Free-space laser communication activities in Europe: SILEX and beyond," in Lasers and Electro-Optics Society, 2006. LEOS 2006. 19th Annual Meeting of the IEEE, 2006, pp. 78-79

Andreas Aristidou, Joan Lasenby, FABRIK: A fast, iterative solver for the Inverse Kinematics problem, Graphical Models, Volume 73, Issue 5, 2011, Pages 243-260, ISSN 1524-0703, https://doi.org/10.1016/j.gmod.2011.05.003.

A New Deal for an Effective European Research Policy. The Design and Impacts of the 7th Framework Programme // Muldur, U., Corvers, F., Delanghe, H., Dratwa, J., Heimberger, D., Sloan, B., Vanslembrouck, S. 2006, XXVI, 289 p.,http://books.google.de/books,id=Ccwyj2vue $5 \mathrm{kC} \&$ printsec=frontcover\&hl=ru\&sou $\mathrm{rce}=\mathrm{gbs} \_a \mathrm{tb} \# \mathrm{v}=$ onepage $\& \mathrm{q} \& \mathrm{f}=\mathrm{fals}$

Davydov D.V., Eprikov S.R., Kirsanov K.B., Pryanichnikov V.E. (2017). Service Robots Integrating Software and Remote Reprogramming, Proceedings of the 28th DAAAM International Symposium, pp.1234-1240, B. Katalinic (Ed.), Published by DAAAM International, ISBN 978-3-902734-11-2, ISSN 1726-9679, Vienna, Austria, DOI: $10.2507 / 28$ th.daaam.proceedings. 172 .

Pryanichnikov V. E. Artificial intelligence and software and hardware robotic systems. Information-measuring and control systems. - 2018. - Vol. 16, No. 12. - Pp. 3-11, ISSN 2070-0814.

Aryskin, A., Davydov, O., Eprikov S., Ksenzenko A., Pryanichnikov, V., Punenkov O.; Shipovalov E. Solovyova M., Stepanova D., Tarasov R. \& Tikhomirov A. (2020). Robotariums implementations witn the Elements of Artificial Intelligence Control, Proceedings of the 31st DAAAM International Symposium, pp.0973-0985, B. Katalinic (Ed.), Published by DAAAM International, ISBN 978-3-902734-29-7, ISSN 1726-9679, Vienna, Austria DOI: 10.2507/31st.daaam.proceedings. 135

V.V. Arykantsev, A. A. Aryskin, O.O. Belyaev, A.Ya. Ksenzenko, E.A.Prysev, V.E. Pryanichnikov, V.V. Chernyshev, S.R.Eprikov. Supervisory control of underwater 
walking apparatus, Extreme robotics and conversion trends. Collection of abstracts of the international scientific and technical conference, 2018, St.Petersburg, p. 203.

A.Y. Ksenzenko, Yu.S. Marzanov, E.A. Prysev, V.E. Pryanichnikov, V.V. Chernyshev, Prototyping of contactless data exchange and power supply of underwater satellite robots with a base station walking on the bottom, Extreme robotics. Collection of abstracts of the international scientific and technical conference, 2017, St. Petersburg, p. 268.

Bielich T., Ksenzenko A. Ya., Kirsanov K. B., Pryanichnikov V. E. Increasing the time of continuous operation of the underwater inspection robotic complex. Informationmeasuring and control systems. 2015, No. 7, pp. 51-56, ISSN 2070-0814.

Ksenzenko A.Y, Prysev E.A., Pryanichnikov V.E., Chernyshev V.V., (2017). Intelligent Robotronics: Design the Contactlees Charger and Contactless Data transfer between underwater Robot-Satellits and Underwater 6-legged Vehicle. Proceedings of the 28th DAAAM International Symposium on Intelligent Manufacturing and Automation, pp. 1197-1201, B. Katalinic (Ed), Published by DAAAD International, ISBN 978-3-902734-08-2, ISSN 1726-9679, Vienna, Austria, DOI: 10.2507/28 th .daaam.proceedings. 166. 